\title{
Experimental Investigation of Heat Transfer Rates and Pressure Drops through Compact Heat Exchangers
}

- Where the Heat Exchanger is Angled Relative to the Incoming Airflow -

\author{
Lisa Henriksson ${ }^{\text {1) }}$ (Erik Dahl ${ }^{2)}$ Peter Gullberg ${ }^{3)}$ Lennart Löfdahl ${ }^{4)}$ \\ 1) - 4) Chalmers University of Technology \\ 41296 Gothenburg, Sweden (E-mail: lisa.henriksson@chalmers.se) \\ 2) - 3) Volvo Trucks \\ 41296 Gothenburg, Sweden
}

Received on July 8, 2014

Presented at the JSAE Annual Congress on May 22, 2014

\begin{abstract}
This paper presents pressure drops and heat transfer rates for compact heat exchangers, where the heat exchangers are angled $90^{\circ}, 60^{\circ}, 30^{\circ}$ and $10^{\circ}$ relative to the incoming airflow. The investigation is based on two heat exchangers with different thicknesses, $19 \mathrm{~mm}$ and $52 \mathrm{~mm}$. The experiments were performed for five airflow rates and five coolant flow rates, where the inlet temperature of the coolant was defined to two temperatures; ambient temperature and $90^{\circ} \mathrm{C}$. The test set-up is defined as having a constant cross-section area for $90^{\circ}, 60^{\circ}$ and $30^{\circ}$ angles, resulting in a larger core area and a lower airspeed through the core, for a more inclined heat exchanger. The investigation showed that the more inclined heat exchangers resulted in lower static pressure drops and at the same time achieved higher heat transfer rates, for a specific mass airflow rate.
\end{abstract}

KEY WORDS: heat fluid / heat exchanger, angled, inclined, heat transfer rate, pressure drop [D1]

\section{Introduction}

The cooling demand for heavy-duty trucks has increased in recent years, along with emissions regulations and market requirements; and is likely to continue increasing. This is also a result of increased engine power together with additional heat sources, such as Exhaust Gas Recirculation, Charge Air Cooler and Waste Heat Recovery. To be able to meet upcoming emissions regulations and market requirements, additional systems will be required and a further increase in cooling demand will be seen. To fulfil the cooling demand, enlarged heat exchangers, multiple heat exchangers or higher heat transfer efficiency is required. In cab-over-engine trucks, the front under-run protection, the cab floor and the main frame, limit the area available for heat exchangers in the front part of the vehicle; together with the tipping function of the cab. This forces the vehicle manufacturers to evaluate other locations for the heat exchangers. A common factor for most of these positions is that the incoming cooling airflow is not perpendicular to the heat exchanger, as is the case for heat exchangers mounted at the front. It is therefore necessary to investigate the airflow behaviour when the air is angled relative to the heat exchanger, as well as how the heat transfer and pressure drop are affected.

There are vehicles today that have the heat exchanger located where the airflow is not necessarily perpendicular. For example some busses have their air intake positioned on the roof or at the side of the vehicle. Alternative cooling module positions have been investigated by for example ${ }^{(1-3)}$. The aerodynamic resistance of the vehicle must also be taken into consideration with new cooling module positions, since they affect the airflow around the vehicle; and the aerodynamic drag increases by the square of the vehicle velocity, becoming dominant above $80 \mathrm{~km} / \mathrm{h}$ for heavy vehicles ${ }^{(4)}$. Earlier investigations regarding angled heat exchangers and airflow characteristics through a heat exchanger have also been carried out, for example ${ }^{(5-7)}$. M Kim et al. ${ }^{(5)}$ performed experiments regarding angled heat exchangers where the exposed core area was constant for each angle, described in Case B in Figure 1. The results from this study were that heat transfer rate was not 
significantly affected and the pressure drop over the installation increased when increasing the angle of the heat exchanger.

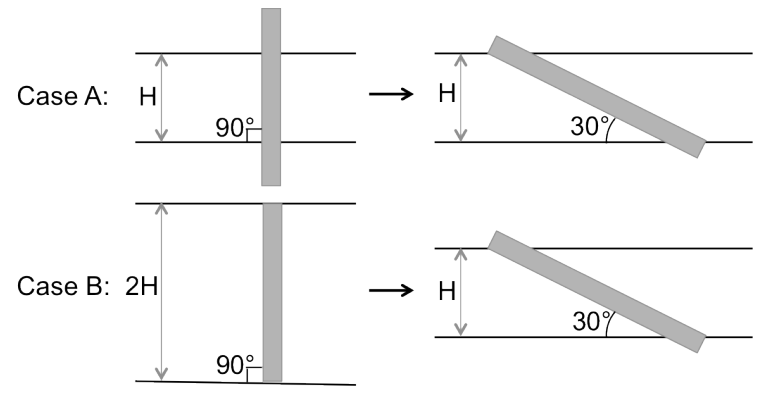

Fig. 1 Definition of the test set-up.

An early investigation carried out by M Nicholds at NACA ${ }^{(6)}$, presented pressure drop data for angled heat exchangers relative to the airflow. The study was based on method Case B in Figure 1. The results showed that the flow losses increased only slightly for angles between $30^{\circ}-90^{\circ}$. Below an angle of $30^{\circ}$ the pressure loss increased drastically. At $30^{\circ}$ the airflow over the heat exchanger was fairly uniform as well. An investigation regarding angled heat exchangers for a Grand Prix racing car was performed by D Rivers et al. ${ }^{(7)}$. The tests were performed for a given duct size, Case A. The conclusion from this work was that the pressure drop was decreased for angles $35^{\circ}-53^{\circ}$, where $35^{\circ}$ was the most inclined heat exchanger. For angles less angled than $53^{\circ}\left(53^{\circ}-89^{\circ}\right)$ the pressure drop was increased compared to the $90^{\circ}$ case. It was also observed that the heat transfer rate followed the same behaviour with a low value for angles of $53^{\circ}-89^{\circ}$ and higher values for angles of $35^{\circ}-53^{\circ}$. Though, it should be noted that the core area is doubled for the $30^{\circ}$ angle and the velocity through the heat exchanger is half compared to the $90^{\circ}$ case.

This article presents results for part of a larger project, involving experiments, 3D Computational Fluid Dynamics (CFD) and 1D simulations. The simulations are carried out for the complete experimental set-up as well as for one period of a louvered fin of the heat exchanger. The later case is carried out to be able to understand the airflow behaviour when the heat exchanger is angled. Previous results are performed by $\mathrm{L}$ Henriksson et al. and are presented in ${ }^{(8-9)}$. The first article focused on comparing pressure drop over the heat exchanger, for $90^{\circ}$ and $30^{\circ}$, obtained from CFD simulations and experiments. Conclusions were that CFD over predicted the pressure drop and the deviation was $6-8 \%$. It was also shown that there should not be any duct mounted behind the heat exchanger, in the experiments, when it is angled. The reason is that it creates a large pressure drop and the results are no longer only dependent on the heat exchanger angle. In this article the airflow characteristics were also presented for the detailed heat exchanger geometry. The second article presents a CFD method to simulate the airflow within the core of the heat exchanger. Detailed airflow characteristics within the core, when the heat exchanger was simulated at different angles, are also presented.

The main purpose with the present investigation was to evaluate experimental results, both static pressure drop and heat transfer rate. Two heat exchanger designs were evaluated with the airflow perpendicular relative to the heat exchanger: $90^{\circ}$ and with an angle of $60^{\circ}, 30^{\circ}$ and $10^{\circ}$. The test section area was defined to be constant, corresponding to Case A in Figure 1. This is the most suitable method when there is a given volume available on the vehicle. It should be kept in mind that there will be a larger core area, exposed to the oncoming airflow, for the more inclined heat exchangers.

\section{Case Definition}

The heat exchanger geometries and the experimental layout, as well as the set-up of the tests are presented in this sub chapter.

\subsection{Heat exchanger geometry}

A compact heat exchanger has a large surface area to increase the heat transfer between the liquid and the air. A crossflow compact louvered heat exchanger consists of flat tubes through which the liquid flows, and louvered fins where the air passes through, see Figure 2. Louvered fins are used in order to break up the boundary layer, increasing the heat transfer rate. For the experiments three specially made compact heat exchangers were manufactured with a frontal core area of $888 \mathrm{~mm} \times 888 \mathrm{~mm}$. This article will consider the results from two of the heat exchangers. Those had a thickness of $19 \mathrm{~mm}$ and $52 \mathrm{~mm}$, with symmetric louvers. Figure 2 illustrates the $19 \mathrm{~mm}$ thick geometry. 


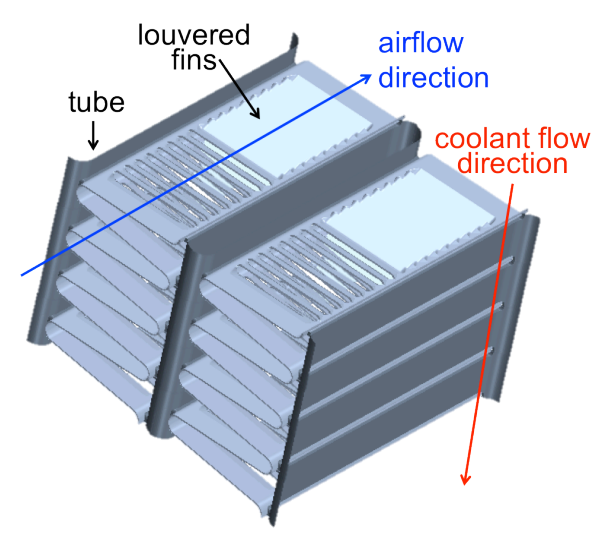

Fig. 2 CAD geometry of the $19 \mathrm{~mm}$ thick heat exchanger, together with the flow directions.

A louvered fin compact heat exchanger is defined by a number of parameters. These are described and presented in Figure 3 for the tested heat exchanger, where part of the louvered fin is seen.

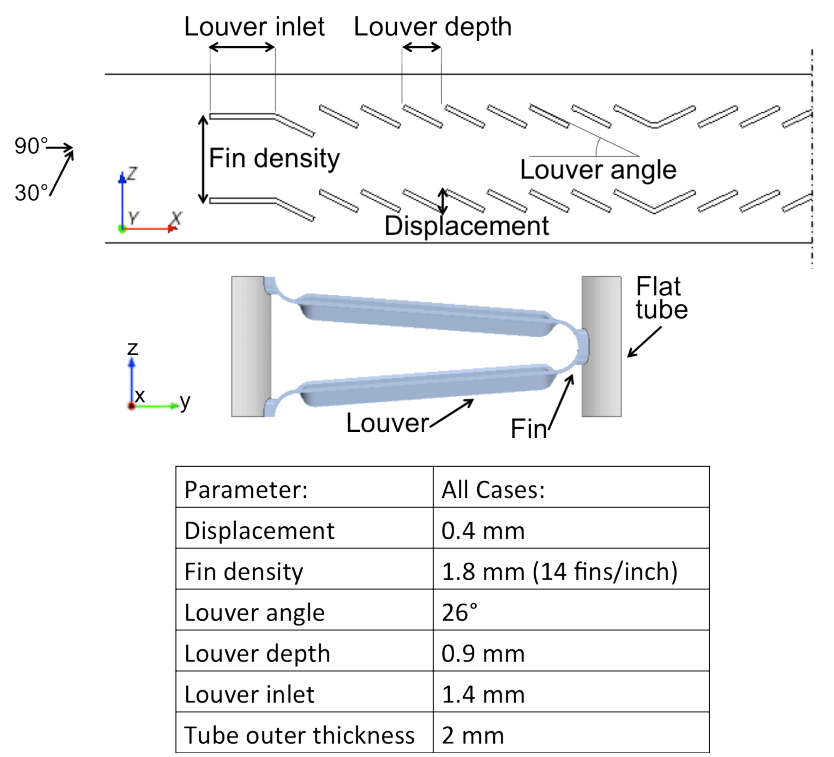

Fig. 3 Definition of parameters for a louvered fin heat exchanger.

\subsection{Experimental set-up}

The experiments were performed at the radiator supplier, TitanX Engine Cooling, where a test set-up was built to test each heat exchanger and angle. They were tested in two directions: the coolant tanks were at the sides of the heat exchanger resulting in a horizontal flow of the coolant; for the other set-up the heat exchangers were rotated $90^{\circ}$, resulting in a vertical flow of the coolant, since the tanks were then at the top and at the bottom. The first scenario is defined as crossflow tests and the second scenario is defined as downflow tests, see Figure 4. The heat exchangers were thereafter angled downwards. It is the results from the crossflow tests that are presented in this article.

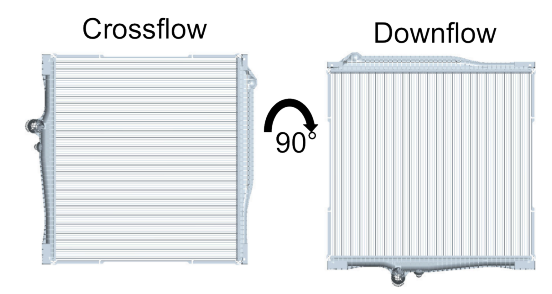

Fig. 4 Definition of crossflow and downflow configurations.

Each heat exchanger was tested with an angle of $90^{\circ}, 60^{\circ}$, $30^{\circ}$ and $10^{\circ}$, relative to the airflow. The width of the duct was constant for all configurations, $888 \mathrm{~mm}$, while the height varied. For the $90^{\circ}, 60^{\circ}$ and $30^{\circ}$ angles it was $444 \mathrm{~mm}$, and for the most inclined heat exchanger, $10^{\circ}$, the height was decreased to $154 \mathrm{~mm}$. The height of the duct was defined by the size of the heat exchanger, were the core of the heat exchanger should be able to be fitted inside for its most angled configuration. Due to the duct height definition, half of the heat exchanger was outside the duct for the $90^{\circ}$ case. Those parts were insulated, as well as the outside of the duct, to avoid heat transfer to the surroundings and air leakage.

The length of the duct in front of the heat exchanger was $1.60 \mathrm{~m}$ and no duct was positioned behind the heat exchanger for the $60^{\circ}, 30^{\circ}$ and $10^{\circ}$ angles. For the $90^{\circ}$ cases, where the airflow was perpendicular to the heat exchanger, an outlet duct was installed. CFD simulations with an outlet duct, have been carried out by L Larsson et al. ${ }^{(8)}$ and the results showed large resistance due to the outlet duct for the angled heat exchangers. To reduce energy losses and to obtain a uniform airflow over the crosssectional area at the duct, a bell-mouth duct was used at the inlet. In Figure 5 the test set-up for the experiments is shown at the top, and a CAD layout is shown at the bottom. The heat exchanger, marked as CHE (Compact Heat Exchanger), is angled in $30^{\circ}$ with the tanks at the sides, crossflow cases, in the top figure. The experimental set-up figure, does not show the inlet since it is positioned on the other side of the wall, as can be see in the CAD figure. 


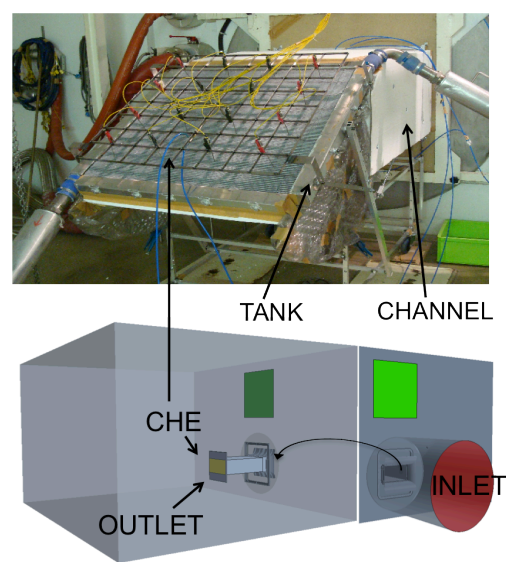

Fig. 5 Experimental set-up.

Sensors measuring temperature, static- and total pressures were mounted in front of, and behind, the heat exchanger. A grid with 16 temperature sensors was mounted behind the heat exchanger, seen in the top figure in Figure 5. To cover the range of possible vehicle operation conditions five mass airflow rates were tested with the range $0.9-4.6 \mathrm{~kg} / \mathrm{s}$; corresponding to an airflow velocity range of $1.9-9.9 \mathrm{~m} / \mathrm{s}$. Due to the lower duct height for the $10^{\circ}$ cases the mass airflow rates were adjusted to obtain the same air speed in the duct, the range being $0.3-1.6 \mathrm{~kg} / \mathrm{s}$. The experiments were performed for five airflow rates and five coolant flow rates, where the temperature of the coolant was defined to two inlet temperatures; ambient temperature, $25^{\circ} \mathrm{C}$, and $90^{\circ} \mathrm{C}$. Five coolant mass flow rates where tested for each angle and for each mass airflow. For the $19 \mathrm{~mm}$ thick heat exchanger the range was $0.7-2.5 \mathrm{~kg} / \mathrm{s}$; and $2.0-7.5 \mathrm{~kg} / \mathrm{s}$ for the $52 \mathrm{~mm}$ thick heat exchanger. These ranges resulted in the same coolant velocity in the tubes for the two heat exchangers. A combination of the airflow rates and the coolant rates resulted in 30 tests per heat exchanger and angle, in total a test matrix of 240 combinations. It should also be mentioned that the tests were performed with water instead of a water-glycol mixture.

The static pressure drop was obtained by measuring the differential pressure between position $\bullet$ and $\mathbf{\square}$, marked in Figure 6. The figure represents the experimental set-up in a $2 \mathrm{D}$ sketch and it should be mentioned that the figure does not have the correct dimensions. Four measuring points are recorded at the entrance position and the averaged value is compared to the pressure at the reference position $\mathbf{\square}$. The static pressure just in front of the heat exchanger is not identical to the pressure at due to the contraction of the airflow at the bell-mouth. From control measurements it is seen that the pressure drop over the bell-mouth inlet is negligible. If an assumption is applied, saying that there are negligible losses at the inlet, the static pressure over the core is the value measured between $\boldsymbol{\nabla}$ and $\mathbf{\square}$ subtracted one dynamic pressure, due to the loss at the exit of the heat exchanger core. This effect must be taken into consideration since the dynamic pressure out from the heat exchanger is not recovered into useful energy. The velocity in the heat exchanger core defines the dynamic pressure. From CFD simulations it has been seen that the airflow uniformity over the heat exchanger is fairly uniform, even thought it is angled.

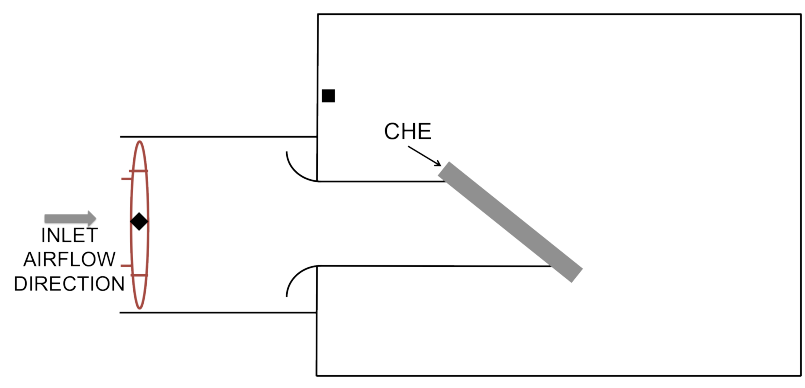

Fig. 6 2D sketch of the experimental set-up and the measuring positions.

The heat transfer rates are calculated by using Equation 1, where the liquid mass flow, $\dot{m}$, in the heat exchanger and the temperature difference, $\Delta \mathrm{T}$, at the entrance and exit of the tanks are measured. The temperatures are measured with a plutonium resistance thermometer $\left(\mathrm{P}_{\mathrm{t}} 100\right)$ and the mass flow is measured with a coriolis mass flow meter.

$Q=\dot{m} c_{p} \Delta T$

\section{Results and Discussions}

In this investigation the pressure drop was defined from the isothermal tests. Due to smaller variations in ambient temperature the static pressure drop values were normalized to an air temperature of $25^{\circ} \mathrm{C}$. When installing an angled heat exchanger in a vehicle the data represented as a function of mass airflow should be analysed. From a theoretically point of view the parameters as a function of air velocity in the core is more appropriate to be studied.

\subsection{Static pressure drop}

The static pressure drop over the heat exchanger core as a function of mass airflow is presented in Figure 7. The first graph represents the results for the $19 \mathrm{~mm}$ thick heat exchanger and the second is for a thickness of $52 \mathrm{~mm}$. It can be seen that the pressure drop follow similar behaviour for all angled heat 
exchangers and that the parameter is decreased for an increased angle. The main reason to the decreased pressure drop for the inclined cases is that the air velocity through the core decreased for the more inclined cases, since the exposed area of heat exchanger in the duct is increased. It is seen that the pressure drop is increased for the $10^{\circ}$ angled cases, compared to the $30^{\circ}$ cases, at the same mass airflow rate. These cases have the same exposed core area in the duct, but the $10^{\circ}$ angled cases were mounted in a lower duct, which had a height of $154 \mathrm{~mm}$. To be able to compare the results for this configuration with the other angles the mass airflow rates can be calculated to a duct height of $444 \mathrm{~mm}$, by keeping the velocity in the duct and core constant. The measured pressure drop value, seen in Figure 7, will then be positioned on the tested mass airflow value multiplied by a factor of $444 / 154$. The curve for the $10^{\circ}$ cases will then be positioned under the $30^{\circ}$ curves.

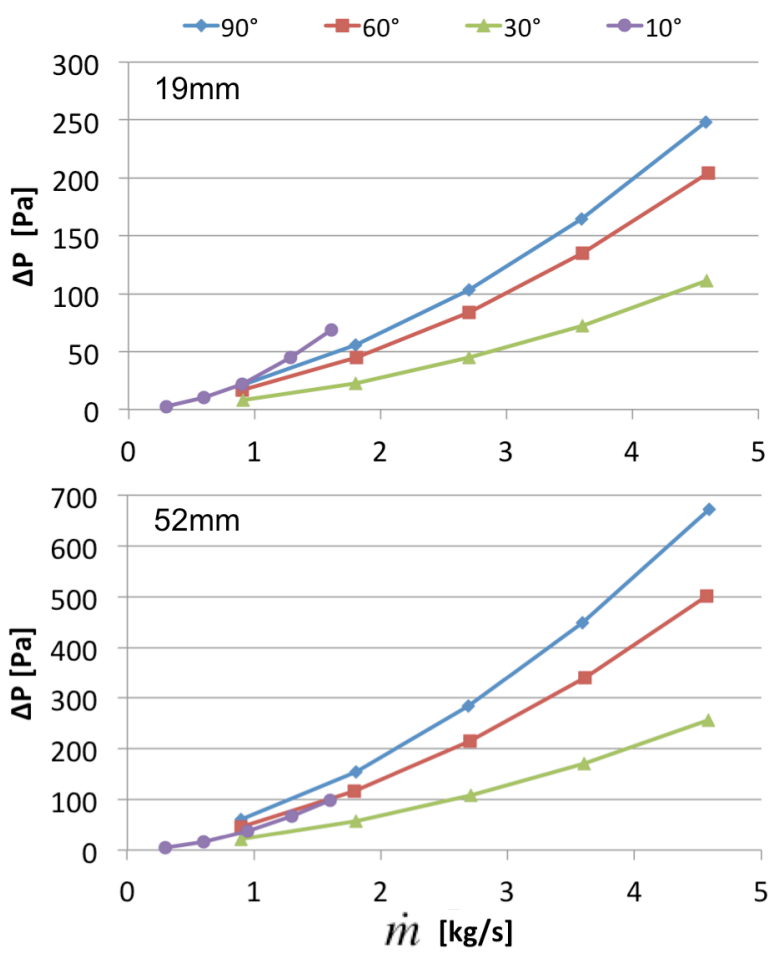

Fig. 7 Static pressure drop for the $19 \mathrm{~mm}$ thick (top) and the $52 \mathrm{~mm}$ thick (bottom) heat exchanger.

The changes in static pressure drop from $90^{\circ}$ to the angled cases were approximately the same for the $19 \mathrm{~mm}$ and the $52 \mathrm{~mm}$ thick heat exchanger. For the $19 \mathrm{~mm}$ heat exchanger the averaged percentage decrease, for all mass airflows, for the $60^{\circ}$ case compared to the $90^{\circ}$ case, was $19 \%$. The corresponding value for the $30^{\circ}$ and $10^{\circ}$ angles were $58 \%$ and $83 \%$. For the $52 \mathrm{~mm}$ heat exchanger the values were $25 \%, 62 \%$ and $90 \%$ respectively. Significant reduction in static pressure drop for the $10^{\circ}$ angled cases, mounted in a duct with a height of $444 \mathrm{~mm}$, were seen as a consequence of the low airspeed through the core.

The pressure drop over a heat exchanger contributes normally by three components; friction loss, acceleration of the medium and losses at the in- and outlet ${ }^{(10)}$. The pressure drop was increased for the thermal experiments, as a consequence of the increase in temperature of the air in the heat exchanger core. The specific volume is increased since the density is decreased, resulting in an accelerating airflow. Due to this effect, together with an increased friction loss, the pressure drop over the core is increased. Since there is an open area behind the heat exchanger, for $10^{\circ}, 30^{\circ}$ and $60^{\circ}$, there are no extra losses behind the heat exchanger. The results show the same trends as the isothermal experiments, even though the values were higher.

When the heat exchanger is angled a larger portion of the core is inside the duct, exposed to the oncoming airflow. This affects the speed of the air through the core and it can be seen in Figure 8 that the highest pressure drop over the core was achieved for a more inclined heat exchanger, at the same air velocity. Though, the $60^{\circ}$ angled heat exchanger with a thickness of $52 \mathrm{~mm}$ resulted in a lower pressure drop than the perpendicular case. This is most likely an effect of the outlet duct, used for the $90^{\circ}$ cases, creating a pressure loss. This result is in-line with previous investigation, e.g. M Kim et al. ${ }^{(5)}$. The angled heat exchanger resulted in a higher pressure drop, mainly due to the higher airflow losses at the inlet of the core ${ }^{(9)}$. The largest contribution to the pressure drop is the first half of the heat exchanger, independent of the heat exchanger angle. In the same technical paper the airflow out from the heat exchanger core was investigated, showing that it has an angle of $4-6^{\circ}$ relative to the perpendicular plane to the heat exchanger. The outlet angle of the airflow is consequence of the angled louvers at the fin. When mounting a duct after the heat exchanger a resistance is created due to the angled airflow from the core, as well as the outlet duct itself. 

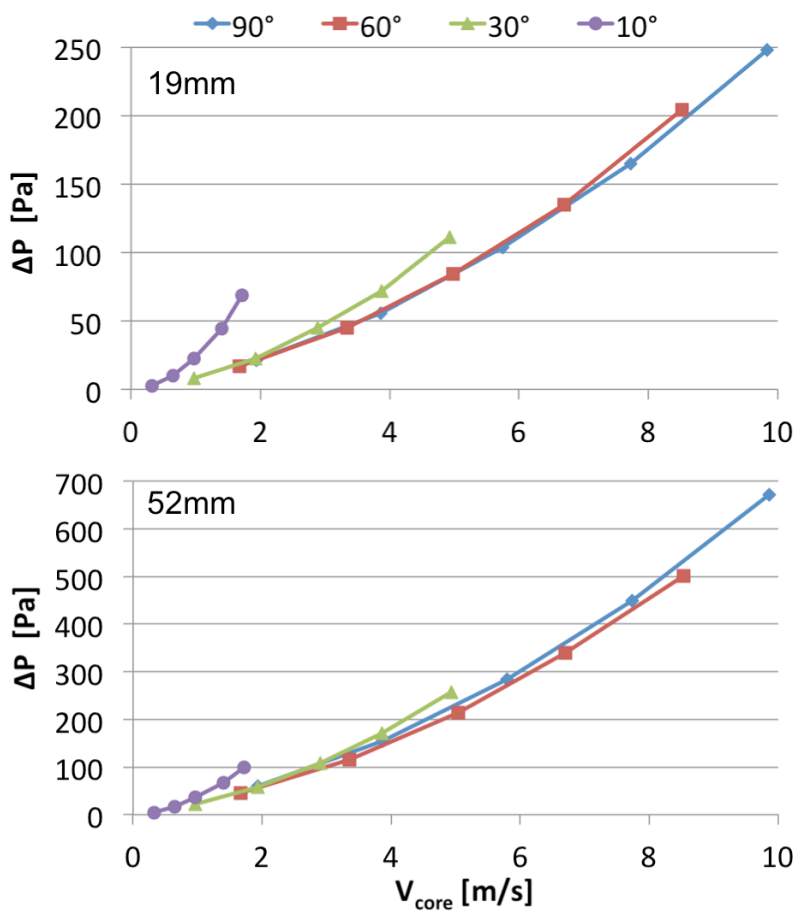

Fig. 8 Static pressure drop as a function of air speed through the heat exchanger core.

\subsection{Heat transfer}

The heat transfer results are shown for the highest liquid mass flow value, in Figure 9. The first graph shows the results for the heat exchanger with a thickness of $19 \mathrm{~mm}$ and the second for $52 \mathrm{~mm}$.
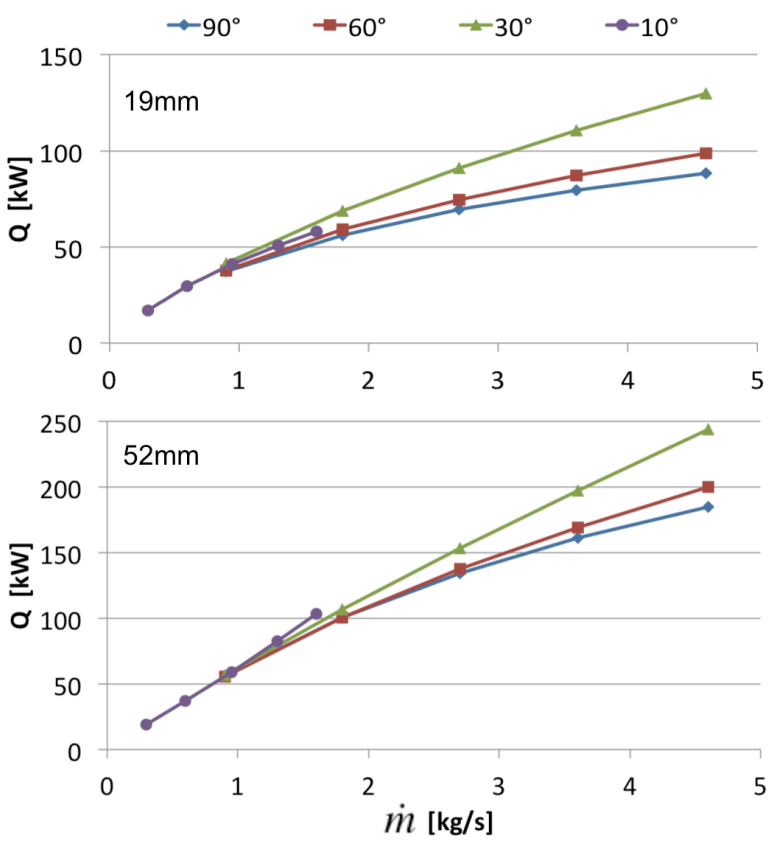

Fig. 9 Heat transfer rate for the $19 \mathrm{~mm}$ thick (top) and the $52 \mathrm{~mm}$ thick (bottom) heat exchanger.
It can be seen from the graphs that the heat transfer rate is approximately constant at a lower mass airflow rate for all angles. The deviation between the angled heat exchangers becomes relevant at higher mass airflow rates. For these values the $30^{\circ}$ angled heat exchanger resulted in the highest heat transfer values. The reason to the similar heat transfer rates at lower mass airflow value is that the coolant already is cooled down to the temperature of the airflow and no more cooling is possible. It is important to bear in mind that the $10^{\circ}$ cases were tested in a smaller duct, even though the whole heat exchanger core was exposed to the oncoming airflow, as it also was for the $30^{\circ}$ configurations.

To be able to compare the heat transfer rate in a more general way, the parameter should be analysed for the same air speed through the heat exchanger core and normalized to the core area in the duct. This parameter as a function of inclination angle is seen in Figure 10, with an air speed of $2.0 \mathrm{~m} / \mathrm{s}$ in the core. It was expected to obtain similar values for all angles, since the air velocity in the core is the same.

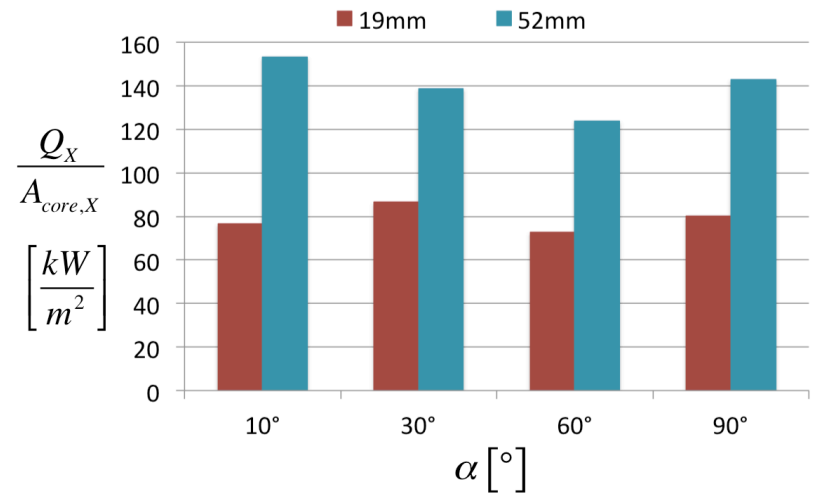

Fig. 10 Heat transfers rate per unit core area, as a function of inclination angle of the heat exchanger.

3.3. Static pressure drop versus heat transfer

To find the most efficient heat exchanger, from both pressure drop and heat transfer rate point of view, these parameters can be plotted together. In Figure 11 the results are presented for the $19 \mathrm{~mm}$ (top) and the $52 \mathrm{~mm}$ (bottom) thick heat exchanger, with the tested mass airflow values for each angle. 

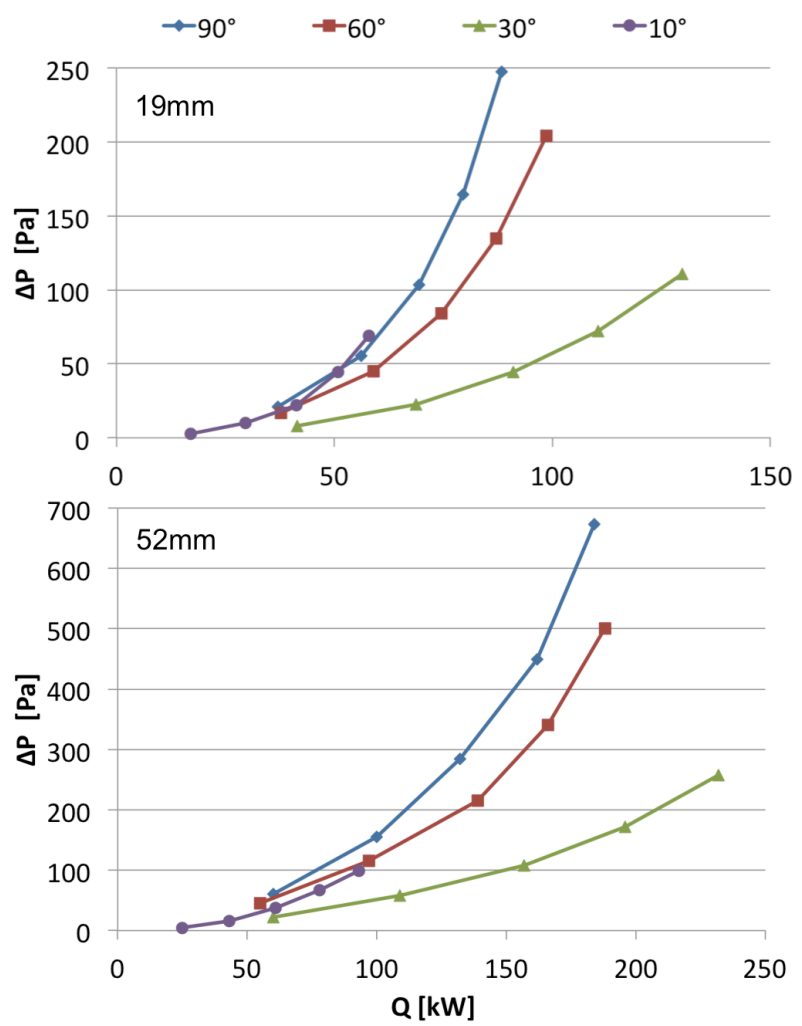

Fig. 11 Static pressure drop as a function of heat transfer, for the $19 \mathrm{~mm}$ thick (top) and the $52 \mathrm{~mm}$ thick (bottom) heat exchanger.

The two heat exchangers behave in a similar way. Both $90^{\circ}$, $60^{\circ}$ and $30^{\circ}$ cases have a significantly steeper slope compared to the $30^{\circ}$ angled cases. The more inclined heat exchangers resulted in higher heat transfer rates and at the same time gave a lower static pressure drop. These results are to be expected since they are not normalized to the heat exchanger area exposed to the oncoming airflow.

\section{Conclusions}

The conclusions from this investigation depend on which way the results are analysed. When seen from a vehicle installation point of view, where the data is plotted against the mass airflow and the core area exposed to the oncoming airflow increases with an increased inclination angle, the $30^{\circ}$ and $10^{\circ}$ cases achieved the lowest static pressure drop. This result is obtained for the $10^{\circ}$ cases when the parameter values are recalculated for a duct cross-section area as the one used for the $90^{\circ}, 60^{\circ}$ and $30^{\circ}$ angled cases. At the same time the $10^{\circ}$ and $30^{\circ}$ cases resulted in the highest heat transfer rates.
If the results are analysed at a specific air speed through the core, it is seen that the angled heat exchangers generated a higher static pressure drop. The reason for this result is that there are larger separated areas at the inlet, at the tube, when the heat exchanger is angled.

The heat transfer rate on the other hand was higher for a more inclined heat exchanger. For these cases a larger core area was subjected to the oncoming airflow.

If all the data is put together and the pressure drop is plotted against the heat transfer for the tested cases, the final conclusion is that the $30^{\circ}$ angled heat exchanger generated the lowest static pressure drop for the same heat transfer rate. This result is obtained when defining the test set-up with a constant crosssection area. If an angled heat exchanger is going to be installed in a vehicle, it has been shown that a larger angled heat exchanger generate both a higher heat transfer rate and a lower static pressure drop. This result is obtained since a larger core area is exposed to the oncoming airflow, increasing the heat transfer rate and decreasing the air speed through the core, decreasing the pressure drop.

\section{Continuing Investigation}

Further research will cover the experimental results for the downflow cases. For these tests a third heat exchanger was investigated as well. This was a specially made heat exchanger with the louvers in only one direction, rather symmetric louvers as is usually the case. 3D CFD and 1D simulations will be performed for all heat exchangers and angles, where both pressure drop and heat transfer will be analysed. After a simulation method is defined intermediate heat exchanger angles can be simulated to find pressure drop and heat transfer rate. Microprobes were mounted inside the core of one of the heat exchanger, to measure the velocity distribution. Those results will be analysed, to investigate the airflow uniformity within the core.

\section{References}

(1) Larsson, L., Investigation of Rear-Mounted Cooling Module Installations for Heavy Vehicles. Licentiate thesis, Chalmers University of Technology, (2011). 
(2) Barnard, R.H., Theoretical and experimental investigation of the aerodynamic drag due to automotive cooling systems, volume 214 Part D, ImechE, (2000).

(3) Santer, R.M. \& Gleason, M.E., The Aerodynamic Development of the Probe IV Advanced Vehicle, SAE Paper 831000, (1983).

(4) Lögdberg, O., Turbulent Boundary Layer Separation and Control, PhD thesis, KTH, (2008).

(5) Kim, M.H., Youn, B. \& Bullard, C.W., Effect of Inclination on the Air-Side Performance of a Brazed Aluminum Heat exchanger under Dry and Wet Conditions, International Journal of Heat and Mass Transfer 44, p. 4613-4623, (2001).

(6) Nichols, M.R., Investigation of Flow Through an Intercooler Set at Various Angles to the Supply Duct, NACA, L-408, (1942). (7) Rivers, D.A., Poulter, J.E. \& Lamont, P.J., Aerodynamics of Inclined Radiators on Grand Prix Cars, Loughborough University of Technology, UK, (1994).

(8) Larsson, L., Dahl, E., Gullberg, P., Skåre, T., Contet, A. \& Löfdahl, L., CFD Simulation and Experimental Investigation of Pressure-Drop through $90^{\circ}$ and $30^{\circ}$ Angled Compact Heat exchangers Relative to the Oncoming Airflow, VTMS11, (2013). (9) Henriksson, L., Dahl, E., Gullberg, P. \& Löfdahl, L., CFD Method and Simulations on a Section of a Detailed MultiLouvered Fin where the Incoming Air is Directed at $90^{\circ}$ and $30^{\circ}$ Relative to the Compact Heat exchanger, SAE Paper 2013-012417, (2013).

(10) Kays, W.M. \& London, A.L., Compact Heat Exchangers, third edition. McGraw-Hill, (1984).

\section{Definitions/Abbreviations}

CHE Compact Heat Exchanger

$\mathrm{c}_{\mathrm{p}} \quad$ Specific heat capacity $[\mathrm{J} /(\mathrm{kgK}]$

$\dot{m} \quad$ Mass flow rate $[\mathrm{kg} / \mathrm{s}]$

$\mathrm{P} \quad$ Static pressure $[\mathrm{Pa}]$

Q Heat transfer $[\mathrm{kW}]$

$\mathrm{T} \quad$ Temperature $\left[{ }^{\circ} \mathrm{C}\right]$ 